\title{
Preparation of Veterinary Premix with Dual Active Ingredients in Granular Form
}

\author{
Andrea Fodor-Kardos ${ }^{1}$ Aurél Ujhidy², Gábor Nagy³ , Béla Gyetvai ${ }^{4}$ Judit Tóth \\ ${ }^{1}$ Research Institute of Materials and Environmental Chemistry, Research Centre for Natural Sciences, H-1117 Budapest, \\ Magyar tudósok körútja 2., Hungary \\ 2 Research Institute of Biomolecular and Chemical Engineering, University of Pannonia, H-8200 Veszprém, Egyetem u. 10., Hungary \\ ${ }^{3}$ Analkrom Ltd., H-1194 Budapest, Zombor u. 57., Hungary \\ ${ }^{4}$ Alpha-Vet Animal Health Ltd., H-8000 Székesfehérvár, Homoksor u. 7., Hungary \\ * Corresponding author, e-mail: toth@mukki.richem.hu
}

Received: 09 June 2021, Accepted: 09 September 2021, Published online: 18 January 2022

\begin{abstract}
The aim of the study was to investigate the preparation of granular veterinary premix containing two different antibiotics by fluid bed granulation process. The particle size and density of the active ingredients were investigated for the proper selection of the filler material. The used antibiotics were tylosin tartarate and colistin sulfate, while isomalt sugar alcohol and cellulose materials were selected as filler and binder, respectively. The colistin sulfate was fed together with the binder solution because of its low density, fine particle size and relatively low (1.2\%) concentration in the product. The type and concentration of the binder in its solution, the feeding rate and the total amount of added binder solution were optimized for obtaining dust free granules with desirable abrasion resistance and good flowability. The active ingredient content for both antibiotics was preserved even at the elevated temperature applied during the fluid granulation process.
\end{abstract}

\section{Keywords}

veterinary premix, dual antibiotics, fluid bed granulation, dust free product

\section{Introduction}

Veterinary premix is a mixture containing one or more active substances and must always be mixed with animal feed before use. The mixture of premix and feed is called medicated feed. Solid premixes exist either as a powder or in granulate form. Powders contain in most cases a dust fraction. Dust is defined as any solid material usually having a particle size less than $100 \mu \mathrm{m}$ [1]. Dust in premixes increases the cost of medicated feed concerning clean up time of mixing equipment and loss of product. Besides that, dust of active ingredients can be irritant and toxic when they get in contact with the operators. They can be harmful to skin, eyes or even to respiratory system. There are facemasks and dust filtering equipment for personal care and usage of carefully chosen wetting process and anti-dust excipients to eliminate this problem [2]. Other possibility is to produce premixes by granulation that is a suitable process for production of particulate materials without dust fraction. Granulation is a size enlargement unit operation where fine particles are agglomerated to form larger granules [3].
Granulation has a wide range of application in different industries such as mineral processing, agricultural products, detergents, pharmaceuticals, foodstuffs and specialty chemicals. Granulation is carried out to improve product functional quality, homogenize materials for the given composition, which are differ in initial characteristics, eliminate dusting during the mixing operations, improve flowability for further processing and handling [4]. Typically, three components are needed for granules preparation: the initial particles or particles mixture (bed), a binder and mixing of the bed and binder. According to the binder nature, granulation processes are classified as wet, dry and melt operations. The mixing process can be mechanical (pans, drums, high shear granulators) or pneumatic (fluidized-, spouted- or rotatory-bed granulators) $[5,6]$. In fluidized bed wet granulation process, the liquid binder (a solution or dispersion) is distributed mainly by spraying onto the bed particles and, subsequently, the granules are dried to evaporate the solvent. There are several process variables that 
determine the produced granules quality. Some important ones are the following: the initial bed particles size, temperature and flow rate of the fluidizing air, binder spraying mode, binder concentration and feeding rate. The chemical composition, viscosity (i.e. the concentration) and the addition rate (the amount) of binder are key operation parameters of the granulation determining the spray droplets and the granules growth [7-9].

Veterinary premixes are sometimes the combination of two antibiotics leading to a synergism and/or other benefits (e.g. decreases the possibility of building resistance of the microorganism sensitive to them). Production of granulated premix with two antibiotics differing in dosage and powder characteristics needs special processing methods. In our experiments tylosin tartarate and colistin sulfate were used as antibiotics. Tylosin is a macrolide antibiotic, its effect is bacteriostatic, prevents protein synthesis of microorganisms. It is extremely effective against Gram-positive bacteria and mycoplasmas. In veterinary medicine, it is currently approved for therapy of bovine mastitis, pneumonia and arthritis in calves, bronchitis and bronchopneumonia in dogs, pneumonia, ileitis and erysipelas in pigs, infectious sinusitis in turkeys and chronic respiratory disease and necrotizing enteritis in chickens [10]. Colistin is a polypeptide antibiotic, acting as a bactericide. Its effect against Gram-negative bacteria is significant. Main indications are infections caused by Enterobacteriaceae in pigs, poultry, cattle, sheep, goats and rabbits [11]. The two ingredients together are rather useful in opposition to a large scale of microorganisms (pathogen mycoplasmas, spirochetes, Streptococcus, Staphylococcus, Pneumococcus, Vibrio, Pasteurella, Corynebacterium, Escherichia, Salmonella, Shigella, Pseudomonas). Tylosine antibiotics are rather stable compared to colistin ones which are heat sensitive in different conditions $[12,13]$.

The aim of this study was to produce granulated veterinary premix without dust fraction containing two different antibiotics and to preserve the active ingredient content that are exposed to heat effect during the fluid bed formulation. Three different cellulose polymers were selected as binder material as they are generally used in food and pharmaceutical granulation processes [14, 15].

\section{Materials and methods}

\subsection{Materials}

Colistin sulfate (COL) and tylosin tartarate (TYL) were purchased from Zhejlang Apolea Kangu Bio-pharm. Co. and Shandong Lukang Shelile Pharm. Co., respectively.
Isomalt (Isomaltidex 16502), hydroxypropyl methylcellulose (Methocel E5 and E15, abbr. are E5 and E15) and hydroxypropyl cellulose (Klucel LF, abbr. is KLF) were provided by Cargill Deutschland $\mathrm{GmbH}$, Colorcon Limited and Ashland Specialty Ingredients, respectively.

\subsection{Equipment and experiments}

The granulation was performed in a fluidized bed granulator of laboratory size $(\mathrm{d}=0.106 \mathrm{~m})$, the schematic set-up can be seen in Fig. 1. Experiments were carried out as follows: batch size was in all experiments $300 \mathrm{~g}$. The bed consisted of $31.50 \mathrm{~g}$ TYL and a given amount isomalt that completed the batch size to $300 \mathrm{~g}$. The bed material was loaded to the fluidization apparatus. The binder solution was prepared of $3.75 \mathrm{~g} \mathrm{COL}, 15.00 \mathrm{~g}$ isomalt and different amount and type of cellulose binder in water.

The binder material concentration in the binder solution $\left(\mathrm{C}_{\mathrm{b}}\right)$ can be seen in Table 1. The particle bed is preheated by air with airflow rate of $6 \mathrm{~m}^{3} \mathrm{~h}^{-1}$ to reach inlet temperature of $80^{\circ} \mathrm{C}$ under stirring rate of $60 \mathrm{rpm}$, these two parameters were constant during the experiments. Once the temperature reached the initial inlet value the binder solution feeding was started with a rate of $3.7-5.0 \mathrm{~g} \mathrm{~min}^{-1}$. The outlet temperature was between $27-40^{\circ} \mathrm{C}$ in the experiments depending on the feeding rate and the concentration of the solutions. The main process parameters of the experiments are summarized in Table 1. The airflow rate was adjusted for keeping a good fluidization profile; its final value was $13-19 \mathrm{~m}^{3} \mathrm{~h}^{-1}$. After

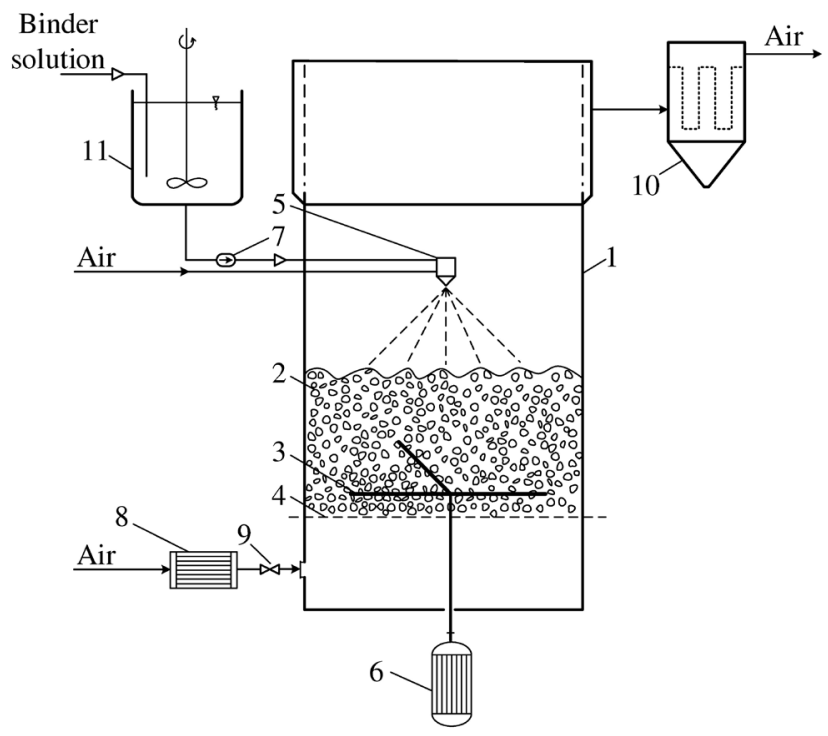

Fig. 1 Schematic drawing of the laboratory granulator unit: 1 granulator unit, 2 fluid bed, 3 impeller, 4 air distributor, 5 atomizer, 6 electric motor, 7 feeding pump, 8 air-heater, 9 air valve, 10 cyclone, 11 binder solution tank 
Table 1 The main process parameters in granulation experiment: mass ratio of binder solution to particle bed $\left(\mathrm{G}_{\mathrm{b}} / \mathrm{G}_{0}\right)$; binder material concentration in binder solution $\left(\mathrm{C}_{\mathrm{b}}\right)$, feeding rate $(\mathrm{F})$, outlet temperature $\left(\mathrm{T}_{\text {out }}\right)$ and powder characteristics of the products $\mathrm{A}-\mathrm{F}$ : average particle size $\left(d_{a v}\right)$, dust fraction $(<0.1 \mathrm{~mm})$, abrasion resistance $(A B \%)$ and moisture content $(M C)$

\begin{tabular}{|c|c|c|c|c|c|c|c|c|c|}
\hline Run & Binder & $\mathrm{G}_{\mathrm{b}} / \mathrm{G}_{0}$ & $\mathrm{C}_{\mathrm{b}}, \mathrm{w} / \mathrm{w} \%$ & $\mathrm{~F}, \mathrm{~g} \mathrm{\operatorname {min } ^ { - 1 }}$ & $\mathrm{T}_{\text {out }},{ }^{\circ} \mathrm{C}$ & $d_{a v}, \mathrm{~mm}$ & $<0.1 \mathrm{~mm}, \%$ & $A B \%$ & $M C, w / w \%$ \\
\hline A & E5 & 0.54 & 3.5 & 5.0 & 27 & 0.49 & 0.21 & 23.00 & 6.1 \\
\hline B & E5 & 0.54 & 5.2 & 3.7 & 35 & 0.35 & 1.07 & 74.00 & 4.1 \\
\hline $\mathrm{C}$ & E5 & 0.66 & 5.4 & 4.2 & 27 & 0.44 & 0.73 & 24.30 & 5.8 \\
\hline D & $\mathrm{KLF}$ & 0.66 & 5.4 & 4.0 & 40 & 0.58 & 0.15 & 46.00 & 4.4 \\
\hline E & E15 & 0.54 & 3.5 & 4.5 & 27 & 0.47 & 1.14 & 25.50 & 8.6 \\
\hline $\mathrm{F}$ & E15 & 0.54 & 5.2 & 4.4 & 30 & 0.65 & 0.61 & 77.80 & 4.6 \\
\hline
\end{tabular}

finishing the feeding of binder solution, the granulated material was dried under stirring rate of $40 \mathrm{rpm}$ until the outlet temperature began to rise (it took 2-6 minutes depending on the moisture content of the particle bed).

The product was removed from the granulator and analysed for flowability, abrasion resistance (of fraction $0.63-0.8 \mathrm{~mm}$ ) and particle size distribution. The active ingredient content was measured in a selected sample.

\subsection{Characterization of initial materials and products} 2.3.1 Density, flowability and abrasion resistance of the granules

Density and flowability: The bulk density of granules and intermediates $\left(\rho_{b}\right)$ was determined by pouring $10 \mathrm{~g}$ of the granules into $100 \mathrm{~mL}$ cylinder and measuring the volume of granules. Tapped bulk density $\left(\rho_{t}\right)$ was determined after tapping the cylinder until no further decrease in the granule volume [16]. To estimate the flowing abilities of the powders Carr index (CI, see Eq. (1)) and Hausner ratio (HR, see Eq. (2)) were calculated:

$\mathrm{CI}=100\left(\rho_{t}-\rho_{b}\right) / \rho_{b}$,

$\mathrm{HR}=\rho_{t} / \rho_{b}$,

$100 \mathrm{~g}$ of the granules was poured into a standard funnel [17] and its outflow time $\left(\mathrm{g} \mathrm{s}^{-1}\right)$ was used as flowability (F1).

Abrasion resistance: The abrasion resistance of granules was determined by fluidization: $20 \mathrm{~g}$ of granules $\left(W_{0}\right)$ with particle size between $0.63-0.8 \mathrm{~mm}$ were filled in a column $(\mathrm{d}=40 \mathrm{~mm})$ and were fluidized for $1 \mathrm{~min}$. These granules were sieved through a $0.63 \mathrm{~mm}$ sieve and reweighed. This weight was designated as $W$. The percent of abrasion resistance $(A S \%)$ was calculated based on the Eq. (3):

$A S \%=100\left(W_{0}-W\right) / W_{0}$.

\subsubsection{Particle size and distribution}

The antibiotics and the matrix materials were fine powders thus their particle size and distribution were determined by laser diffraction method. Laser diffraction determines the particle size distributions by measuring the angular variation in intensity of light scattered as a laser beam passes through a dispersed particulate sample. The angular scattering intensity data is then analysed to calculate the size of the particles responsible for creating the scattering pattern using the Mie theory of light scattering. The particle size is reported as a volume equivalent sphere diameter marked as $d_{v}$.

The measurements were carried out in wet dispersion in cyclohexane by Malvern Mastersizer 2000 instruments using the Hydro 2000 SM dispersion unit with $1200 \mathrm{rpm}$ mixing rate. Mie theory requires knowledge of the optical properties as refractive index (RI) of the solid sample and of the dispersant, and the imaginary component $(\mathrm{Ab})$ of the refractive index of the material. The used optical parameters for calculation were the following: isomalt 1.300 and 0.1 ; COL 1.575 and 0.1; TYL 1.575 and 0.0 as RI and Ab, respectively. The particle size and distribution of the granules were measured by sieving: $50 \mathrm{~g}$ samples were shaken for $600 \mathrm{~s}$ using sieves of $0.1,0.2,0.4,0.63,0.81 .0,1.6$ and $2.0 \mathrm{~mm}$ sizes for particle size distribution determination and the weighted average particle size was calculated $\left(d_{a v}\right)$. Criteria for dust fraction was $<1.0 \mathrm{w} / \mathrm{w} \%$ for particles $<0.1 \mathrm{~mm}$.

\subsubsection{Viscosity measurements of the binder polymers}

Viscosity was measured on an A\&D Vibro Viscosimeter (Tokyo, Japan) at $25^{\circ} \mathrm{C}$. Solutions were prepared in concentration of $3,4,5$, and $7 \mathrm{w} / \mathrm{w} \%$ from each binder polymer.

\subsubsection{Moisture content of the granules}

Moisture content (MC, w/w\%) was measured using a moisture analyzer (Sartorius AG, Germany): $1 \mathrm{~g}$ of granules was dried at $105^{\circ} \mathrm{C}$ using steady-state mass conditions. 


\subsubsection{Determination of active ingredient content}

The analytical method was developed, validated and described based on EMEA regulations: [18, 19], briefly.

TYL content determination: dissolved/sampled solutions of pH 4.5, External Standard was used Tylosin CRS, Council of Europe, European Pharmacopoeia, Lot No.: 1. Analytical method was HPLC - UV detection with conditions: column of $250 \times 4.6 \mathrm{~mm}, 5 \mu \mathrm{m}$, TRACER EXTRASIL ODS2 (Technokroma), wavelength: $280 \mathrm{~nm}$, acetonitrile (HPLC grade): methanol (HPLC grade): $0.005 \mathrm{M}$ ammonium dihydrogene phosphate $=70: 20: 10$.

COL content determination: dissolved/sampled solutions of $\mathrm{pH} 4.5$ and OPA (ortho-phthalaldehyde) derivatization procedure and reversed phase HPLC determination using fluorescence detection. External Standard: Colistin sulfate CRS, Council of Europe, European Pharmacopoeia, Lot No.: 3a, purity: $86.9 \%$. Analytical method: HPLC - fluorescence detection: HPLC column: Hyperprep $10 \mathrm{C} 18 \mathrm{HS}$ (BST, Hungary), length: $250 \mathrm{~mm}$, internal diameter: $4.0 \mathrm{~mm}$, Particles diameter: $10 \mu \mathrm{m}$, wavelength: $\lambda_{\mathrm{ex}}=330 \mathrm{~nm}$, $\lambda_{\text {em }}=440 \mathrm{~nm}, 83 \mathrm{~V} / \mathrm{V} \%$ methanol (HPLC grade, Merck); $12 \mathrm{~V} / \mathrm{V} \%$ double distilled water; $5 \mathrm{~V} / \mathrm{V} \%$ cc. acetic acid and $5.5 \mathrm{~g} / 1$ heptane-1-sulfonic acid sodium salt.

The difference in active ingredient content was calculated as a relative percentage ratio to the required concentration. The accepted margin of error was $\pm 5 \%$. The experiments were carried out in triplicate.

\section{Results and discussion}

\subsection{Selection of carrier, binder materials and binder addition method}

Veterinary premixes are medicated mixtures of one or more active substances and matrix of carrier and other additives used for the formulation. Selection viewpoints for the materials are chemical and physical compatibility between the excipients and the active substances depending on the formulation process of the premixes. For carrier material isomalt was selected as a not reducing sugar alcohol with high chemical stability and low hygroscopicity [20]. The particle size and density of the filler and the active material are very important parameters for the granulation process. Materials used as a mixture in the fluid bed with very different physical characteristics can cause particle segregation during fluidization [21]. The two antibiotics and the carrier materials are fine powders with an average particle size under $50 \mu \mathrm{m}$. TYL and isomalt have a very similar size distribution and density. COL contains higher fraction of finer particles with an average particle size $21.14 \mu \mathrm{m}$ and it is a very light powder with a tapped density of $0.368 \mathrm{~g} \mathrm{~cm}^{-3}$. Data of the volume mean diameter, density and calculated CI and HR values were given in Table 2, the particle size distribution can be seen in Fig. 2.

The estimated flowability of the intermediates are different according to CI and HR data but all of them showed poor flowing characteristics, i. e. they did not flow through the standard funnel (see in Section 2.3.1.).

In premix the concentration of the antibiotics was adjusted 10.50 and $1.25 \mathrm{w} / \mathrm{w} \%$ for TYL and COL, respectively. The low concentration active ingredients $(<2 \%)$ can be dissolved in binder solution instead of mixing to the particle bed together with the other ingredients [22].

During the granulation experiments COL was fed together with the binder because of its low concentration, its very fine particle size and density for avoiding the segregation from the particle bed. It means that in the binder solution the required amount of COL was also dissolved. COL has a good water solubility but very bad wettability as well as the cellulose type binders. Different sugars are often used for aiding wettability of powders [23]. For improved wettability, COL and the binder material were mixed with isomalt before dissolving. Three different cellulose type binders, E5, E15 and KLF were selected in the experiments.

E5 and E15 are hydroxypropyl methylcellulose with different molecular weight of 28,700 and 60,000 Da,

Table 2 Volume mean diameter $\left(\mathrm{d}_{\mathrm{v}}\right)$, density data $\left(\rho_{b}, \rho_{t}\right)$ Carr index (CI) and Hausner ratio (HR) of isomalt, TYL and COL

\begin{tabular}{lccccc}
\hline Ingredients & $\mathrm{d}_{\mathrm{v}}, \mu \mathrm{m}$ & $\rho_{b}, \mathrm{~g} \mathrm{~cm}^{-3}$ & $\rho_{t}, \mathrm{~g} \mathrm{~cm}^{-3}$ & $\mathrm{CI}$ & $\mathrm{HR}$ \\
\hline Isomalt & 37.23 & 0.488 & 0.650 & 24.92 & 1.33 \\
TYL & 49.26 & 0.348 & 0.609 & 42.86 & 1.75 \\
COL & 21.17 & 0.300 & 0.368 & 18.48 & 1.23 \\
\hline
\end{tabular}

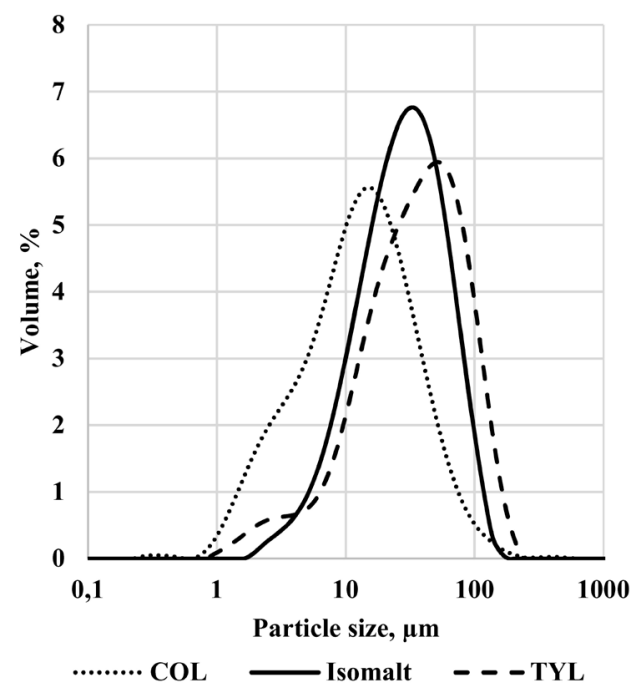

Fig. 2 Particle size distribution of the ingredients 
respectively [24]. KLF is chemically different cellulose derivative, hydroxyl propyl cellulose with molecular weight of 90,000 Da. E15 and KLF have similar viscosities, but E5 has remarkable lower viscosities in solutions at same concentrations than the other two binders. The viscosity vs concentration curves are seen in Fig. 3.

\subsection{Granulation process and products properties}

The product physical characteristics are determined by the following process and operation parameters during granulation:

- the material properties of the bed,

- the bed materials particle size and distribution,

- the binder material characteristics,

- the binder solution concentration, i.e. viscosity,

- the relative amount of the binder solution (i. e. the mass ratio of binder to particle bed),

- the feeding rate of the binder solution,

- the temperature of the fluidization air.

In our experiments the bed material properties and the inlet temperature of the air were kept constant (see in Subsection 2.2). Different operation parameters were the binder solution addition rate (3.7-5 $\mathrm{g} \mathrm{min})$, the binder concentration in the solution $(3.5-5.4 \mathrm{w} / \mathrm{w} \%)$ and the binder solution relative amount to the bed (0.54-0.66), detailed data are in Table 1. The average particle size, the ratio of dust fraction $(<0.1 \mathrm{~mm})$, the abrasion resistance, the flowability and moisture content of the products A-F can be seen in Table 1.

In experiment $\mathrm{A}, \mathrm{B}$ and $\mathrm{C} \mathrm{E} 5$ binder was used in a concentration of $3.5,5.2$ and $5.4 \mathrm{w} / \mathrm{w} \%$, respectively. The experiments A and B were carried out using the same amount of binder solution with different binder concentration. The abrasion resistance of product A was very low,

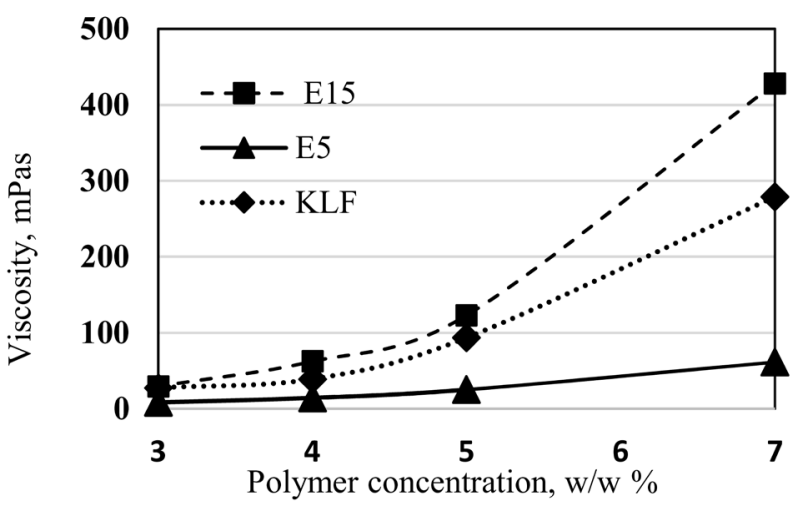

Fig. 3 Dependence of viscosity on polymer concentration of E5, E15 and KLF i.e. $23 \%$. That's why in experiment B higher concentration of the binder E5 was used with lower feeding rate for better wetting condition of the particles bed, i.e. to ensure the binder to build solid bridges strength enough to stay stable after drying. Generally, the higher amount and concentration of the binder resulted in higher agglomeration ratio in the product. In our case the abrasion resistance improved during the better wetting of the particle bed, but the particle size and the dust fraction were not suitable. In experiment $\mathrm{C}$ higher concentration and added ratio (0.66) of the binder resulted in a similar average particle size and abrasion resistance to product $\mathrm{A}$. The initial average particle size of the ingredients in particle bed was 30-50 $\mu \mathrm{m}$ (see Table 2). The viscosity in experiment $\mathrm{C}$ was $25 \mathrm{mPa}$ s (calculated from the viscosity vs binder concentration curve Fig. 3.) Keningley et al. [25] found that to form granules with calcium carbonate and silicone oils, a minimum binder viscosity was required: the size of the powder particles increased from $8 \mu \mathrm{m}$ to $230 \mu \mathrm{m}$ changing the viscosity from $1 \mathrm{mPa}$ s to $1 \mathrm{~Pa} \mathrm{~s}$. This indicates that an interaction between powder particle size and binder viscosity might be important in order to control the agglomerate growth. Better process conditions were found in experiment D using KLF binder material (viscosity is already $100 \mathrm{mPas}$ ), though the abrasion resistance was not satisfactory enough (46\%). Good abrasion resistance was reached in experiments B using E5 (hydroxypropyl methylcellulose type) binder, however, for the higher agglomeration rate higher viscosity of binder solution was needed. That's why in experiments E and F E15 was used as binder, the viscosities were 40 and $120 \mathrm{mPa}$ s in experiments, respectively. The moisture content was in all experiments under $10 \%$ (see in Table 1) that is an expected value for feed premixes to inhibit the infections of microorganism [26].

Dust free product, where the ratio of the particles under $0.1 \mathrm{~mm}$ was $<1 \mathrm{w} / \mathrm{w} \%$, with an acceptable (77.8\%) abrasion resistance was obtained in experiment $\mathrm{F}$ using $\mathrm{C}_{\mathrm{b}}=5.2 \%(\mathrm{w} / \mathrm{w})$ E15 and $\mathrm{G}_{\mathrm{b}} / \mathrm{G}_{0}=0.54$ during granulation. Another important characteristic of the granular product is their improved flowability comparing to the intermediates. The calculated CI and HR data were between 13.75-18.75 and 1.16-1.23, respectively, estimating a good flowability after granulation [27]. The measured flowability was in all A-F products good, varied between $3.03-3.60 \mathrm{~g} \mathrm{~s}^{-1}$. The detailed data are presented in Table 3. The moisture content was in all experiments under $10 \%$ (see in Table 1) that is an expected value for feed premixes to inhibit the infections of microorganism [27]. 
Table 3 Density $\left(\rho_{b}, \rho_{t}\right)$, measured flowability $(F l)$ and calculated $\mathrm{CI}$ and HR values of granular products

\begin{tabular}{lccccc}
\hline Run & $\rho_{b}, \mathrm{~g} \mathrm{~cm}^{-3}$ & $\rho_{t}, \mathrm{~g} \mathrm{~cm}^{-3}$ & $\mathrm{CI}$ & $\mathrm{HR}$ & $F l, \mathrm{~g} \mathrm{~s}^{-1}$ \\
\hline A & 0.320 & 0.276 & 13.75 & 1.16 & 3.30 \\
B & 0.336 & 0.273 & 18.75 & 1.23 & 3.16 \\
C & 0.320 & 0.261 & 18.44 & 1.23 & 3.03 \\
D & 0.354 & 0.298 & 15.82 & 1.19 & 3.20 \\
E & 0.355 & 0.295 & 16.90 & 1.20 & 3.60 \\
F & 0.355 & 0.302 & 14.93 & 1.18 & 3.18 \\
\hline
\end{tabular}

Granule $\mathrm{F}$ reached the required quality parameters, that's why it was selected for active ingredient content determination. The difference between the required and measured concentration were $2.68 \pm 0.67 \%$ for TYL and $2.45 \pm 0.27 \%$ for COL fulfilled the value of $\pm 5 \%$ as accepted margin of error.

A simplified flowchart of the process is presented in Fig. 4.

\section{Conclusion}

The particle size and the density of the ingredients were investigated for the selection of suitable composition of particle bed and binder solution and adding mode using two different antibiotics in the granulation process. Tylosin tartarate and the selected isomalt filler was loaded together to the particle bed because of their very similar powder characteristics. Colistin sulfate was fed together with the binder solution to avoid particle segregation due to its finer particle size and density, furthermore for its low concentration. For preparation of the binder solution isomalt filler was used as well as for aiding the wettability

\section{References}

[1] World Health Organization. Occupational and Environmental Health Team "Hazard Prevention and Control in the Work Environment: Airborne Dust", Occupational and Environmental Health, Department of Protection of the Human Environment, World Health Organization, Geneva, Switzerland, Rep. WHO/SDE/ OEH/99.14, 1999. [online] Available at: https://apps.who.int/iris/ handle/10665/66147 [Accessed: 07 September 2021]

[2] Mellor, S. "A simple additive settles premix dust problems", Feed Tech, 7(4), pp. 13-14, 2003. [online] Available at: https:// www.allaboutfeed.net/PageFiles/10795/001_boerderij-download-AAF10711D01.pdf [Accessed: 07 September 2021]

[3] Manga, M. S., Willis, D., Ali, N. M., York, D. W. "The impact of raw material properties and process conditions on the color of a powdered formulated detergent product", Particuology, 45, pp. 35-41, 2019.

https://doi.org/10.1016/j.partic.2019.01.002

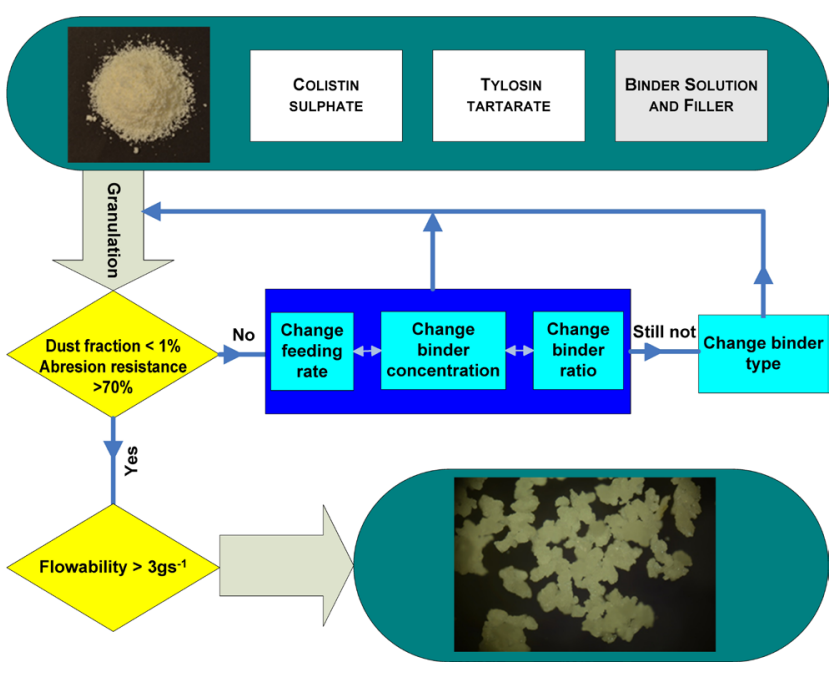

Fig. 4 Flowchart of the granulation process

of colistine sulfate and the cellulose-type binders during the preparation of the binder solution. Changing the binder concentration (binder viscosity), the binder ratio to particle bed, the feeding rate and binder type resulted in product with acceptable characteristics. A dust free product (particle fraction under $0.1 \mathrm{~mm}$ was $0.6 \%$ ) with an acceptable abrasion resistance $(77.8 \%)$ and good flowability was obtained using $\mathrm{C}_{\mathrm{b}}=5.2 \mathrm{w} / \mathrm{w} \%$ ) E15 and $\mathrm{G}_{\mathrm{b}} / \mathrm{G}_{0}=0.54$ variable process parameters during the granulation. The active ingredient content difference from the required concentration in the granules was below $5 \%$ as accepted margin of error for both antibiotics, exactly $2.68 \pm 0.67 \%$ for TYL and $2.45 \pm 0.27 \%$ for COL.

[4] Kamińska, J., Dańko, J. "Analysis of the Granulation Process Mechanism - Stand and Scope of Experimental Investigations", Metallurgy and Foundry Engineering., 37(1), pp. 81-87, 2011. https://doi.org/10.7494/mafe.2011.37.1.81

[5] Veliz Moraga, S., Villa, M. P., Bertín, D. E., Cotabarren, I. M., Piña, J., Pedernera, M., Bucalá, V. "Fluidized-bed melt granulation: The effect of operating variables on process performance and granule properties", Powder Technology, 286, pp. 654-667, 2015. https://doi.org/10.1016/j.powtec.2015.09.006

[6] Pathare, P. B., Baş, N., Byrne, E. P. "Comparison of quality parameters of granola produced by wet granulation with commercially available product", Food and Bioproducts Processing, 90(4), pp. 729-736, 2012.

https://doi.org/10.1016/j.fbp.2012.01.004

[7] Osborne, J. D., Sochon, R. P. J., Cartwright, J. J., Doughty, D. G., Hounslow, M. J., Salman, A. D. "Binder addition methods and binder distribution in high shear and fluidised bed granulation", Chemical Engineering Research and Design, 89(5), pp. 553-559, 2011.

https://doi.org/10.1016/j.cherd.2010.08.006 
[8] Pathare, P. B., Baş, N., Fitzpatrick, J. J., Cronin, K., Byrne, E. P. "Production of granola breakfast cereal by fluidised bed granulation", Food and Bioproducts Processing, 90(3), pp. 549-554, 2012. https://doi.org/10.1016/j.fbp.2011.08.004

[9] Roy, P., Vashishtha, M., Khanna, R., Subbarao, D. "Variation of granule mass fraction with coordination number in wet granulation process", Particuology, 7(5), pp. 408-413, 2009. https://doi.org/10.1016/j.partic.2009.07.001

[10] Buß, M., Feßler, A. T., Turnidge, J., Peters, T., Schwarz, S. "Quality control ranges for tylosin $30 \mu \mathrm{g}$ and $15 \mu \mathrm{g}$ discs applicable to Staphylococcus aureus ATCC ${ }^{\circledR} 25923$ ", Journal of Antimicrobial Chemotherapy, 69(1), pp. 277-280, 2014.

https://doi.org/10.1093/jac/dkt309

[11] European Medicines Agency, Science Medicines Health "Updated advice on the use of colistin products in animals within the European Union: development of resistance and possible impact on human and animal health", European Medicines Agency, Science Medicines Health, London, UK, Rep. EMA/231573, 2016. [online] Available at: https://www.ema.europa.eu/en/documents/ scientific-guideline/updated-advice-use-colistin-products-animals-within-european-union-development-resistance-possible_ en.pdf [Accessed: 07 September 2021]

[12] Mutasim Elimam, M., Wagiealla Shantier, S., Ahmed Gadkariem, E., Awadalla Mohamed, M. "Derivative Spectrophotometric Methods for the Analysis and Stability Studies of Colistin Sulphate", Journal of Chemistry, 2015, Article ID: 624316, 2015.

https://doi.org/10.1155/2015/624316

[13] Hsieh, M. K., Shyu, C. L., Liao, J. W., Franje, C. A., Huang, S. K., Chang, Y. J., Shih, P. Y., Chou, C. C. "Correlation analysis of heat stability of veterinary antibiotics by structural degradation, changes in antimicrobial activity and genotoxicity", Veterinarni Medicine, 56(6), pp. 274-285, 2011. https://doi.org/10.17221/1548-VETMED

[14] Wüstenberg, T. "Cellulose and Cellulose Derivatives in the Food Industry: Fundamentals and Applications", Wiley-VCH Verlag GmbH \& Co., Wienheim, Germany, 2014. https://doi.org/10.1002/9783527682935

[15] Shokri, J., Adibkia, K. "Application of Cellulose and Cellulose Derivatives in Pharmaceutical Industries", In: Van De Ven, T. G. M. (ed.) Cellulose: Medical, Pharmaceutical and Electronic Applications, InTechOpen, City of Publishing, Croatia, 2013, pp. 47-66. https://doi.org/10.5772/55178

[16] Shah, R. B., Tawakkul, M. A., Khan, M. A. "Comparative Evaluation of Flow for Pharmaceutical Powders and Granules", AAPS PharmSciTech, 9(1), pp. 205-258, 2008. https://doi.org/10.1208/s12249-008-9046-8

[17] ASTM International "ASTM B213-03 Standard Test Method for Flow Rate of Metal Powders", ASTM International, West Conshohocken, PA, USA, 2013. https://doi.org/10.1520/B0213-03
[18] European Agency for the Evaluation of Medicinal Products "EMEA/CVMP/573/00-FINAL Notice to Applicants, Veterinary Medicinal Products: Establishment of Maximum Residue Limits (MRLs) for Residues of Veterinary Products in Foodstuffs of Animal Origin: Development and Validation of a Proposed Regulatory Method", The European Agency for the Evaluation of Medicinal Products, London, UK, 2005.

[19] The European Agency for the Evaluation of Medicinal Products, Veterinary Medicines Evaluation Unit "CVMP/VICH/591/98FINAL Guideline on validation of analytical procedures: Methodology", The European Agency for the Evaluation of Medicinal Products, Veterinary Medicines Evaluation Unit, London, UK, 1998. [online] Available at: https://www.ema.europa. eu/en/documents/scientific-guideline/vich-g12-validation-analytical-procedures-methodology-step-7-consensus-guideline_en.pdf [Accessed: 07 September 2021]

[20] Fritzsching, B., Luhn, O. "Isomalt: Applications in the Formulation of Powder Dosage Forms", Innovations in Pharmaceutical Technology, 38, pp. 68-71, 2011. [online] Available at: http:// www.iptonline.com/articles/public/BENEO.pdf [Accessed: 07 September 2021]

[21] Rao, A., Curtis, J. S., Hancock, B. C., Wassgren, C. "Classifying the fluidization and segregation behavior of binary mixtures using particle size and density ratios", AIChE Journal, 57(6), pp. 1446-1458, 2011.

https://doi.org/10.1002/aic.12371

[22] Démuth, B., Fülöp, G., Kovács, M., Madarász, L., Ficzere, M., Köte, Á., Szabó, B., Nagy, B., Balogh, A., Csorba, K., Kaszás, G., Nagy, T., Bódis, A., Marosi, G., Nagy, Z. K. "Continuous Manufacturing of Homogeneous Ultralow-Dose Granules by Twin-Screw Wet Granulation", Periodica Polytechnica Chemical Engineering, 64(4), pp. 391-400, 2020. https://doi.org/10.3311/PPch.14972

[23] Ben Abdelaziz, I., Sahli, A., Bornaz, S., Scher, J., Gaiani, C. "Dynamic method to characterize rehydration of powdered cocoa beverage: Influence of sugar nature, quantity and size", Powder Technology, 264, pp. 184-189, 2014. https://doi.org/10.1016/j.powtec.2014.05.031

[24] Keary, C. M. "Characterization of METHOCEL cellulose ethers by aqueous SEC with multiple detectors", Carbohydrate Polymers, 45(3), pp. 293-303, 2001. https://doi.org/10.1016/S0144-8617(00)00263-0

[25] Keningley, S. T., Knight, P. C., Marson, A. D. "An investigation into the effects of binder viscosity on agglomeration behaviour", Powder Technology, 91(2), pp. 95-103, 1997. https://doi.org/10.1016/S0032-5910(96)03230-5

[26] European Patent Office "Tylosin animal feed premix", CA 2111 899, 2003.

[27] PowderProcess.net, Engineering Resources "Carr index / Hausner Ratio", [online] Available at: https://powderprocess.net/Powder_ Flow/Carr_Index_Hausner_Ratio.html[Accessed: 07 September 2021] 